\title{
Online Identities in Politics. Technological and Content-Based Approach
}

\author{
Zoltán SZÜTS ${ }^{1}$ \\ Eszterházy Károly Catholic University \\ Budapest, Hungary \\ e-mail: szuts.zoltan@uni-eszterhazy.hu
}

\begin{abstract}
In this study, we examine a particular form of organizational identity, the issue of political organizational identity. We have chosen a technology and content-based approach and are looking for the answer to how technology influences identity formation, what role social media plays in shaping online political communities, and what characterizes a definable and strong online political identity. The impact of new communication technologies and media platforms has now reached all levels of society. It has influenced many aspects of everyday life, transformed politics, the economy, and culture, and has an impact on institutional identities as well. To identify the forces shaping institutional identity, we examine the role of digitalization, network technologies, and algorithms and the presence of social media and, finally, bring the Occupy Wall Street movement as an example of reshaping online identities.
\end{abstract}

Keywords: online identities, social media, political communication, OWSM

\section{Introduction}

On 28 October 2021, Mark Zuckerberg, the CEO of Facebook, introduced Meta, a new idea which will focus on bringing the metaverse to life and on helping people connect, find communities, and grow businesses in a virtual (meta-)environment. The metaverse is an extended version of today's online social experiences, now extended to three dimensions and projected into the physical world. It will allow users to share immersive experiences with other users, even when they cannot be together. If the venture is successful, individual identities will multiply in the future, and the physical world will be augmented by (a) digital one(s). Therefore, we do not have to wait long for the extended identities predicted in science fiction

1 The researcher was supported by the János Bolyai Research fellowship of the Hungarian Academy of Sciences. 
movies. In our study, we will explore the path to the digital identity of the present and how this identity has been captured and/or taken hostage by politics through social media. The digital identity we are exploring was born in the information society.

Manuel Castells examined economic and cultural changes in the information society environment in the light of the relationship between individuals and the dynamics of virtual communities, and his works are used as a reference point. He was not, of course, the only author to investigate the interaction between the Internet and culture and society at the global level, David Bell (2001) identifying new types of cultural practices and community-forming causes. The digital personality (identity) is rooted in Internet culture, which is already following new patterns of behaviour and leaving a digital footprint in the world. This personality now moves much more easily within vertical than horizontal structures and finds it difficult to recognize itself in the context of traditional institutions and structures, thus requiring a specific approach. In addition to the disappearance of gatekeepers, we are also witnessing a counter-process, an attempt at total control and regulation. This control is taking place at the level of government, corporations, the arts, and the public sphere, and it is increasingly being seen alongside issues of freedom of expression and freedom of the press (Lessig, 2008; Goldsmith-Wu, 2006).

\section{The Power of Identity in the Online World}

According to Castells (2011), in the information society, power is distributed in a way similar to the nature of the Internet. Castells argues that identity has a prominent role in anchoring the meaning. Power lies in the digital codes of information rather than in the classical centres of power, and as these codes are constantly changing, the nature of power becomes increasingly unstable. In our view, the same can be said of identities. Seen through the lens of digital code, personal identities are increasingly reduced to the digital footprint of users, while organizational identities are shaped by the world of social media, the community of users, and the will of algorithms.

\section{The Impact of Being Digital}

Let us look at the domain of online identity, the Internet and its social impact. György Csepeli and Gergő Prazsák summarize the changes triggered by the Internet as follows: identities are multiplying, global presence is spreading, and social processes are moving to the Internet. As a result of the convergence of spheres of life, the fields of private, public, business, political, cultural, and even religious 
are converging. At the same time, the boundaries of the self are blurring, the contours of groups are fading, grassroots organizations are becoming dominant, and a new public sphere is emerging (Csepeli-Prazsák, 2013). This new technological paradigm has also brought a spatial rearrangement with the emergence of virtual space and an immediate struggle by organizations to occupy it. At the level of the individual, this means that from the 2000s onwards, the daily life of more and more citizens has become a series of online actions. Its pace was first dictated by e-mails and nowadays mostly by messages from real-time chats and social media to smart device notifications. The Internet has shrunk distances, and in this new world communities are global rather than local, with technological links rather than geographical ones connecting members. At the organizational level, too, the creation of online identities has begun. The idea is that the organization (government, political party, corporation, church) most successful in promoting its own narrative will be able to dominate the online space. The rivalry between the United States and Russia in 2021 can also be identified in the struggle between the online identities of the two presidents.

In order to successfully undertake a study of online identity, let us first look at the changes caused by digitalization and networking. The term "creative disruptive technology" is used to describe the potential for increased information flows and data processing in the ecosystem composed of infocommunications technology, digital content, computer networks, and interactive platforms. Creative disruption through digitalization is bringing about the emergence of methods, solutions, and practices that redefine past traditions in the economic, social, cultural, and political subsystems. ${ }^{2}$ A new type of lies, the deep fake puts disinformation at the heart of political communication, while the most popular online video service, Netflix, has become a storyteller capable of taking any ideology to the farthest corners of the world, with users paying for it. In the process of creative disruption, digital technology has reinforced different aspects of existing practices. These include accelerated and instantaneous access, algorithm-driven content dispersion, and a highly efficient and extensive online system of recommendation based on community members.

The impact of new communication technologies and media platforms has now penetrated all levels of society. It has reshaped politics, the economy and culture, institutions, families, and individual identities (Krajcsi, 2000). The changes have brought many benefits to those who possess the rich repository of information literacy - the citizens of the information society -, but not all individuals benefit equally. In the present, the unequal use of ICTs and unequal access to opportunities excludes more than ever before many people from taking advantage of the benefits that flow from the application of new technologies in many areas of social life

2 Digitalization is also having a significant impact on the sciences - see natural sciences (Horváth et al., 2010; Ruszkai et al., 2021). 
(Mancinelli, 2008). When the Internet entered everyday life in the 1990s, previously unknown members of society began to communicate intensively online. This communication was often based on shared interests and a commitment to certain topics and ideas. Personal relationships in the physical world were joined by online virtual communities brought to life by networking. As Szilárd Molnár points out, the study of the process whereby personal relationships are being increasingly marginalized in modern societies and the significance of the primary communities based on them (family, neighbours, friends) is gradually declining plays a decisive role in the history of sociological thought (Molnár, 2007). Reliability, credibility or the lack of it, the role of human-machine communication, and the transformation of physiological needs have come to the foreground. At the bottom of Maslow's hierarchy of needs, Internet access and smartphone use appeared, the problem of processing information overload became a problem to be solved, the always online state became a new way of life, and the issue of free access to information came into focus. The real power used to lie not only in the possession of information but also in the cultural codes embedded in the network and in the knowledge of these codes, but in the present it lies in online identities, the narratives associated with them, and the stories told to construct them.

The social movements of the 1990s and the 2000s began to actively and effectively use the tools of online communication, digital media, and networking. Like social and cultural systems, movements built horizontal relationships between autonomous individuals, later groups, communities, and, finally, organizations. Movements have been organized through mailing lists, websites, and collaborative networking technologies and from the mid-2000s onwards through social media (see Occupy Wall Street). The distributed or decentralized networks that emerged often overlapped, reaching users from different social backgrounds and connecting them across continents around common ideologies, causes, or issues.

\section{The Impact of Technology on Online Identities}

Algorithms have been optimizing socially embedded processes for decades only to come to the fore in the context of social media. Recipes used in cooking are as much algorithms as mathematical equations or musical sheets. Computer code is an algorithm, YouTube's recommendation system is an algorithm, even artificial intelligence itself is an algorithm. As such, current developments in artificial intelligence go beyond traditional algorithms and are now self-programming systems. Systems - machines - are now capable of self-learning. Algorithms can answer mathematical problems, save lives and money, show the way out of heavy traffic, help reduce hate speech, and display the content that users find most compelling. While all of this happened invisibly in the past, the spread of 
digitalization - reaching critical mass - has raised questions about the extent to which the world, society, and human destinies within it are governed by algorithms.

Algorithms are creating new centres of power in social media. Power is now in the hands of those who not only have the information but can process it and recognize patterns in the chaotic flood of data. At the same time, algorithms allow political organizations to tailor their online identity to the individual preferences of their users. YouTube's recommendation system is also based on individual behaviour. The algorithm looks at what a user watched in the past and what other users in the same category watch. Categories, hashtags (\#), and keywords also play a role in recommended content on social media. Social media algorithms treat engagement (in terms of likes, comments, and shares) as a kind of snowball effect. That is, the more engagement a content receives, the more likely the algorithm is to reward it and show it to more users, but algorithms can also categorize users to show the element of a political organization's online identity that they believe is positive for users.

There is a special link between artificial intelligence and politics. The impact of new technologies on politics is already being felt. The Internet and social media forums, which were expected to increase freedom, are opening up a wide window of opportunity for attacks on democracy.

Social media has become a new battleground for political conflict and thus for political identities. In the current social media space, harmful and manipulative political content is spreading faster and more widely than ever before. This is particularly evident in the use of political memes. In political communication, memes are multimedia content designed to politically engage an internal group and/ or antagonize an external group, and they are primarily distributed via social media.

\section{The Public Sphere and Online Political Identities}

The public sphere is traditionally defined as the intermediary between society (its constituent citizens) and the state. The modern civic public sphere is generally defined as the totality of citizens in a society and as an institutionalized social space in which citizens exercise freedom of assembly, association, and expression while attempting to control political institutions (Habermas, 1962). In modern civil states, the public sphere is also the basis for social communication. Political organizations with online presence can offer a successful alternative to currently dominant forms of power, including global markets, international institutions, and states. The Internet and new forms of social media have radically changed the structure and ways of social communication. The public sphere has thus become much broader than before, with new topics, ways of speaking, and speakers emerging in the online environment. 
In social media, two-way, decentralized communication, essentially independent of time and space, allows for the empowerment of opinions and voices that have been marginalized in traditional mass media and for the weakening of previously established power structures. First forums, then blogs and video sharing, and, finally, social networking sites allow for more intense debate than ever before on issues of importance to small groups of individuals. The very nature of the public sphere means that participants raise issues that they feel are important to the community and try to exchange views publicly. Ideally, the number of participants in such debates is unlimited, and anyone can take part in the discussion. The desirable condition is that everyone has access to the public discourse and that participation is not linked to status or position. Participation in the debate should not be subject to technical constraints and should not require special expertise. In this way, public communication is a mutual interaction of all citizens in an understandable linguistic environment. Access to smartphones by almost all members of society also ensures access to the public sphere to a significant extent. The low technical threshold allows people from different groups in society to participate in discussions, but users with similar opinions exclude other opinions from their environment, thus living in echo chambers or opinion bubbles. The idea of an opinion bubble is closely rooted in the media theory of selective perception and retention, according to which individuals favour news sources that reinforce their own opinions and exclude or delay the reception of news that contradict them. Social media, like much of the Internet, reinforces users' pre-existing opinions and political views by essentially surrounding themselves online (by joining communities) with a series of bans on individuals who think similarly to them. Users often delete, ban, or mute friends on Facebook whose (political) content they disagree with. Basically, they are building a big bubble around themselves on the Internet, the cortex of which Facebook is slowly cementing. A machine algorithm monitors the likes that users give out, and the system recommends in advance content they like. The site thus traps individuals in a bubble of opinions, because after a while all they see is a confirmation of their own thoughts and beliefs.

Social media platforms provide direct access to an unprecedented amount of content. Originally designed to entertain users, these platforms have changed the way information is disseminated. Indeed, algorithms mediate and influence content promotion based on users' preferences and attitudes. This paradigm shift has had an impact on the construction of social perceptions and the framing of narratives; it can influence policy making, political communication, and the evolution of public debates. Indeed, online users tend to favour information that aligns with their worldview, ignore divergent information, and form polarized groups around common narratives. Furthermore, when the degree of polarization is high, misinformation and fake news spread rapidly. 


\section{Building an Online Identity}

For political organizations, consistency, a unique voice and style, a strong and distinctive appearance that can be differentiated from the rest are important for building up an effective online political identity. The definition of an online identity should take into account the topic that can be associated with the organization and the level at which the organization is active (local, regional, or global). An organization's online presence can never be an end in itself, so it is necessary to define its objectives (raising awareness, generating constructive debate, promoting results and good practices, solving problems, amplifying inaudible voices). It is also necessary to decide who the target audience for the communication is. The target depends on the content, style, and tone of the communication, which will make up the organization's online identity. The media in general, and social media in particular, are characterized by an overabundance of information and an overwhelming supply of information. Originality is achieved through an original style, a provocative but not offensive tone, a unique vision, and an unconventional approach. If the content (user-generated content - UGC) is highly experience-rich, the algorithms will rank it first. Experientiality is high when the community spends a lot of time on a post and engages in activity.

Since 2010, social media influencers have also been activists. An influencer is a content creator who has become an opinion leader on social media (Facebook, Instagram, YouTube, Twitter, TikTok), able to influence the actions of the community around him/her in the material world, for example, to engage in political activism. An influencer needs to gain and keep the trust of the community, and this is facilitated by their continued presence, credibility, and consistency in advocating for specific issues and causes. High-impact influencers reach a large number of users with their own content: text posts, pictures, videos, blog and vlog posts. A political organization can also build its identity effectively from the narrative created by its community of influencers.

Social media is all about communication, interaction, and immediacy, as well as a broad horizon of information. For a blogger, vlogger, or influencer, belonging to a political organization, immediacy means keeping up with the comments of their community, reacting to a high-profile event. Authenticity means not publishing false information, not producing fake news, as this is the only way to expose it. Experiential means that the followers, who over time form a community, enjoy reading the posts. This is achieved by evoking emotions. The timing and reception varies between platforms, with Facebook generally being used after work, Instagram being followed at basically any time of the day because of the short messages, YouTube videos requiring audio, and blogs being a longer form of entertainment.

In these communities, there are strong and weak relationships. Strongly interacting people form self-contained, closed groups, islands, networked by 
weak ties. According to Paul Lazarsfeld's research in the 1940s, traditional mass communication cannot directly influence people's opinions because they discuss what they see on TV and what they read in the newspapers, so there are two stages of influence (Lazarsfeld, 1948). People basically listen to the opinions of those around them. However, in social media, even strangers with weak connections can influence each other - hence the influencing power of influencers.

\section{The Example of the Occupy Wall Street Movement}

The OCCUPY WALL STREET! (OWSM) started in New York in 2011. In addition to occupying the street that is home to banks and investors, protesters also occupied the virtual space. The protests proved that social networking sites are becoming a new tool for forming online communities. The main reason for this is that they are less under the control of the mainstream media, as they are mostly produced by private individuals rather than professionals, and they require much less financial investment than professional press.

One of the immediate precedents of the Occupy Wall Street movement is the resentment that has been building up among citizens that the financial crisis of 2008 - although it had a major impact on society - has provoked relatively little protest. While investment bankers enjoyed unprecedented profits and bonuses, they continued to receive substantial support from the US government even after the collapse of the system. Seeing the failure of consolidation and the rise to even higher positions of those who caused the crisis, some US citizens began to protest. This led first to the occupation of Wall Street and later to the occupation of New York and other major cities. Occupy Wall Street was a movement of unexpected, often humorous solutions that briefly transformed the US public sphere and reshaped the digital view of politics (Conover et al., 2013). The rapid spread of messages on Twitter allowed the movement to quickly build a physically dispersed, networked counter-public that could articulate its critique of power outside the traditional media (Penney-Dadas, 2014).

The movements of the 1990s and 2000s began to actively use the tools of online media, networking, and online identity. Like social and cultural systems, movements built horizontal relationships between autonomous individuals and later groups and communities. The flow of information became freer and the democratic debate in the online space allowed members of online communities to participate in decisions. In this new cultural, social, and technological paradigm, individuals often made sense of the world around them through communication with others. Movements were organized through mailing lists, websites, and collaborative networking technologies (and, from the mid-2000s, social media). The resulting distributed or decentralized networks often overlapped, reaching and 
connecting users from different social strata across continents. Although mailing lists are still an effective tool today, three social media platforms - Facebook, YouTube, and Twitter - have become the primary channels of communication. In contrast to mailing lists, which provide interaction for closed groups, social media is used by activists to deliver short messages while being able to transmit information and links quickly, cheaply, and very efficiently. The six-step distance and the viral nature of news dissemination help them to do this (Juris, 2012). With the emergence of new types of global activism, online media technologies have played a significant role in the dynamics of these movements. During the 1999 protests against the WTO in Seattle, everyday observers noticed that participants were using mailing lists, websites, and mobile phones to organize very effectively. The Occupy Wall Street movement spread to hundreds of locations around the physical world, made possible by social media campaigns. In addition to a central Facebook page, users created more than 400 individual profiles to spread the movement across the US, including each state's own page. More than 170,000 active users participated in the campaign, and posts about the occupation received more than 1.4 million likes (Caren-Gabi, 2011).

\section{Closing Remarks}

Online identity and popularity are linked, as people like to follow those who espouse certain ideas, styles, or attitudes. Authenticity is an element of online identity, which is why the spread of false information and fake news, inappropriate debate, and the use of fake profiles are a constant threat to an online identity. Personal relationships in the real world have been joined by online communities brought to life by networking.

\section{References}

Bell, D. (2001). An Introduction to Cybercultures. London: Routledge.

Caren, N.-Gaby, S. (2011). Occupy Online. Facebook and the Spread of Occupy Wall Street. SSRN 2011. <https://papers.ssrn.com/sol3/papers.cfm?abstract_ id $=1943168>$ [Accessed on 20 November 2021].

Castells, M. (2011). The Power of Identity 14. Hoboken: John Wiley \& Sons.

Conover, M. D.-Ferrara, E.-Menczer, F.-Flammini, A. (2013). The Digital Evolution of Occupy Wall Street. PloS One 8(5): e64679. <https://journals.plos.org/plosone/ article?id=10.1371/journal.pone.0064679> [Accessed on 20 November 2021].

Csepeli, Gy.-Prazsák, G. (2013). Örök visszatérés? 2.o. [Eternal Recurrence? 2.0.]. Budapest: Apeiron. 
Goldsmith, J.-Wu, T. (2006). Who Controls the Internet? Illusions of a Borderless World. New York: Oxford University Press.

Habermas, J. (1962). Strukturwandel der Öffentlichkeit. Untersuchungen zu einer Kategorie der bürgerlichen Gesellschaft. Frankfurt am Mein: Suhrkamp.

Horváth, Sz.-Jankó Szép, I.-Makra, L.-Mika, J.-Pajtók-Tari, I.-Utasi, Z. (2010). Effect of Evapotranspiration Parameterisation on the Palmer Drought Severity Index. Physics and Chemistry of the Earth, Parts A/B/C 35(1-2): 11-18. https:// doi.org/10.1016/j.pce.2010.03.015.

Introducing Meta: A Social Technology Company. (2021). <https://about.fb.com/ news/2021/10/facebook-company-is-now-meta/> [Accessed on 20 November 2021].

Juris J. S. (2012). Reflections on \#Occupy Everywhere. Social Media, Public Space, and Emerging Logics of Aggregation. American Ethnologist 39(2): 259-279.

Krajcsi, A. (2000). Az internettel kapcsolatos régi problémák. Jel-Kép 3: 3-10.

Lawrence, L. (2008). Free Culture: The Nature and Future of Creativity. <https:// lessig.org/product/free-culture/> [Accessed on 20 November 2021].

Mancinelli, E. (2008). e-Inclusion in the Information Society. Information Society: From Theory to Political Practice: Course book. Budapest: Gondolat-Új Mandátum. Molnár, Sz. (2007). A magyar információs társadalom fejlődése a társadalmi tőke szempontjából. Eszmélet 75(19): 43-55.

Penney, J.-Dadas, C. (2014). (Re)Tweeting in the Service of Protest: Digital Composition and Circulation in the Occupy Wall Street Movement. New Media \& Society 16(1): 74-90.

Ruszkai, Cs.-Pajtók Tari, I.-Patkós Cs. (2021). Possible Actors in Local Foodscapes? Sustainability 13(4): 2080. https://doi.org/10.3390/su13042080.

Wellman, B. (2002). The Internet in Everyday Life. Hoboken: Wiley Blackwell.

\section{Cite as:}

Szúts, Z. (2021). Online Identities in Politics. Technological and Content-Based Approach. Acta Universitatis Sapientiae, Communicatio 8: 60-69. DOI: 10.2478/auscom-2021-0005. 